\title{
Metarhizium Anisopliae Challenges Immunity and Demography of Plutella xylostella
}

\author{
Junaid Zafar ${ }^{1,+}{ }^{1}$, Rana Fartab Shoukat ${ }^{1,+}{ }^{+0}$, Yuxin Zhang ${ }^{1}$, Shoaib Freed ${ }^{2}$, Xiaoxia $\mathrm{Xu}^{1}$ and \\ Fengliang Jin 1 ,* \\ 1 Laboratory of Bio-Pesticide Creation and Application of Guangdong Province, College of Plant Protection, \\ South China Agricultural University, Guangzhou 510642, China; jz_jaam@yahoo.com (J.Z.); \\ ranafartab@gmail.com (R.F.S.); listzhang@163.com (Y.Z.); xuxiaoxia111@scau.edu.cn (X.X.) \\ 2 Laboratory of Insect Microbiology and Biotechnology, Department of Entomology, Faculty of Agricultural \\ Sciences and Technology, Bahauddin Zakariya University, Multan 66000, Pakistan; sfareed@bzu.edu.pk \\ * Correspondence: jflbang@scau.edu.cn; Tel.: +86-208-528-0203 \\ + These authors contributed equally to this work.
}

Received: 28 July 2020; Accepted: 9 October 2020; Published: 13 October 2020

Simple Summary: The diamondback moth, Plutella xylostella, is a destructive pest of cruciferous crops worldwide. Integrated pest management (IPM) strategies, largely involve the use chemical pesticides which are harmful for the environment and human health. In this study, the virulence of three species of entomopathogenic fungi were tested. Metarhizium anisopliae proved to be the most effective by killing more than $90 \%$ of the population. Based on which the fungus was selected to study the host-pathogen immune interactions. More precisely, after infection, superoxide dismutase (SOD) and phenoloxidase (PO), two major enzymes involved in immune response, were studied at different time points. The fungus gradually weakened the enzyme activities as the time progressed, indicating that physiological attributes of host were adversely affected. The expression of immune-related genes (Defensin, Spaetzle, Cecropin, Lysozyme, and Hemolin) varied on different time points. Moreover, the fungus negatively impacted the development of the host by reducing the life span and egg laying ability. Thus, $M$. anisopliae can become a potent prospect for the control of this pest. This information will also reinforce the development of policies for biocontrol-based pest management.

\begin{abstract}
Entomopathogenic fungi are naturally existing microbes, that can serve as a key regulator of insect pests in integrated pest management strategies. Besides having no hazardous effects on the environment, these entomopathogens are alternatives to synthetic insecticides that can control notorious insect-like Plutella xylostella, a destructive pest of cruciferous crops. Three different species of entomopathogenic fungi were evaluated before the selection (high larval mortality and least $\mathrm{LC}_{50}$ ) of Metarhizum anisopliae. The study was designed to investigate the mortality, development, and immune responses of P. xylostella when challenged with $M$. anisopliae, a naturally existing soil-borne entomopathogenic fungus. M. anisopliae resulted in high pest mortality by killing $93 \%$ of larvae. However, no statistically significant effect on hemocyte concentration was observed. The activity of enzymes (Phenoloxidase and Superoxide dismutase) and immune genes (Defensin, Spaetzle, Cecropin, Lysozyme, and Hemolin) did vary at different time points (24, 48, 72 and $96 \mathrm{~h}$ ) after exposure to M. anisopliae. Disturbance in the biological cycles of P. xylostella was also detected, significantly shorter adult life span (8.11:6.87, M:F) and reduced fecundity (101 eggs/female) were observed along with disturbed larval and pupal duration. Results suggest that M. anisopliae can efficiently hinder the P. xylostella defense and developmental system, resulting in mortality and disturbed demography.
\end{abstract}

Keywords: entomopathogenic fungi; genes; mortality; pathogenicity; demography 


\section{Introduction}

Entomopathogenic fungi are naturally existing microbial control agents that effectively regulate the insect pest populations [1,2]. Several entomopathogenic fungi have been used to control insect pests from different orders such as Diptera [3,4], Hemiptera [5], Coleoptera [6], Homoptera [7], and Lepidoptera [8]. The excessive and injudicious use of synthetic insecticides has resulted in pest resurgence, environment degradation, resistance development while also causing harmful effects to human health [9-11]. Such detrimental effects of chemical insecticides stressed the need to develop alternative control strategies. Furthermore, the resistance to insecticide curbed the control strategies, whereas insect pests are unable to develop resistance against entomopathogenic fungi making them an effective weapon against resilient pests [12-16].

Plutella xylostella, one of the most destructive lepidopteran pests of cruciferous crops, has caused severe economic damages (quantitative and qualitative), with an annual cost estimated to be USD 4-5 billion [17-20]. Over the years the pest has developed resistance against many control agents including dichloro-diphenyl-trichloroethane (DTT) and Bacillus thuringiensis (Bt) [21-23] making it difficult to control while also emphasizing the need to develop alternative control strategies. Among all the current strategies, biological control represents an eco-friendly approach with no hazardous effects on human health. Entomopathogenic fungi are biological control agents which are cosmopolitan in nature [1,24-28]. Metarhizium anisopliae, a soil-borne entomopathogenic fungus, represents an ecologically safe alternative to chemical pesticides [29]. The entomopathogen has proven to be effective against lepidopteran pests such as Helicoverpa armigera [30] and Spodoptera exigua [31]. M. anisopliae produces secondary toxins such as Destruxin A and E to repress the host immune responses while also deploying evasion protein such as Mcl1 protein (Metarhizium collagen-like protein) to avoid detection [32,33]. In response to the invasion of microbes, an array of recognition molecules detects the pathogen, resulting in the initiation of Toll and immune deficiency (Imd) pathways, that regulate anti-fungal and antibacterial defenses respectively [34,35]. Spaetzle, a gene encoding toll activating protease, initiates the immune pathway. Defensins are antimicrobial peptides responding to pathogenic challenges or injury. Similarly, cecropins constitute a major part of the insect innate immune system. Antioxidant enzymes such as superoxide dismutase (SOD), a key factor in host defense system, function in melanization and phagocytosis [36,37]. Likewise, Phenoloxidase (PO) is a key enzyme in the melanization cascade that also participates in cuticle sclerotization and wound healing $[38,39]$. In this study, we investigated the efficacy of $M$. anisopliae against $P$. xylostella. The present study aims to explore the interaction of entomopathogenic fungi with its insect host and elaborate the immune and developmental changes after the infection.

\section{Materials and Methods}

\subsection{Insect and Fungi Culture}

The population of P. xylostella was taken from the Institute of Plant Protection, Guangdong Academy of Agricultural Sciences, China by the Engineering Research Centre of Biological Control Ministry of Education, South China Agricultural University, Guangzhou, Guangdong Province, P. R. China. The colony was maintained in a pathogen-free environment. Larvae were kept at $25 \pm 1{ }^{\circ} \mathrm{C}$ with a light: dark cycle of 16:8 h and 60-70\% relative humidity [34]. Three different entomopathogenic fungi were obtained from the Laboratory of Insect Microbiology and Biotechnology, Bahauddin Zakariya University, Multan, Pakistan (Table 1), and screened against P. xylostella. To prevent aging, isolates were passage through the host [40]. Monoconidial culture (14 days) grown on potato dextrose agar (PDA) was harvested with a disinfected spatula in 0.05\% Tween-80 (Sigma-P1754) solution [10,41]. The calculation of spores was done by using a hemocytometer $[42,43]$. Stock solutions were kept at $4{ }^{\circ} \mathrm{C}$ and used in serial dilution for making the desired concentration of entomopathogenic fungi. 
Table 1. Isolates of entomopathogenic fungi from Pakistan.

\begin{tabular}{|c|c|c|c|}
\hline Fungi & Source & Location (Pakistan) & Coordinates \\
\hline Metarhizium anisopliae & Soil & Multan, Punjab & $30^{\circ} 05^{\prime} 11.65^{\prime \prime} \mathrm{N} 71^{\circ} 39^{\prime} 15.65^{\prime \prime} \mathrm{E}$ \\
\hline Beauveria bassiana & Soil & Multan, Punjab & $30^{\circ} 05^{\prime} 11.65^{\prime \prime} \mathrm{N} 71^{\circ} 39^{\prime} 15.65^{\prime \prime} \mathrm{E}$ \\
\hline Isaria fumosorosea & Soil & Multan, Punjab, & $30^{\circ} 05^{\prime} 11.65^{\prime \prime} \mathrm{N} 71^{\circ} 39^{\prime} 15.65^{\prime \prime} \mathrm{E}$ \\
\hline
\end{tabular}

\subsection{Screening of Entomopathogenic Fungi}

Three different entomopathogenic fungi were screened out against $P$. xylostella. Five concentrations $\left(4 \times 10^{8}, 4 \times 10^{7}, 4 \times 10^{6}, 4 \times 10^{5}, 4 \times 10^{4}\right.$ spores $\left./ \mathrm{mL}\right)$ were prepared (hit and trial method) while aqueous 0.05\% Tween-80 (Sigma-P1754) was taken as control [41]. The application of entomopathogenic fungi was done by dipping the larvae in desired concentrations. After dipping, larvae were placed on filter paper for drying and then placed in disinfected plastic dishes (5 $\mathrm{cm}$ diameter) [34]. Fifteen larvae (3rd instar neonates) were exposed to each concentration. The experiment was repeated four times. A sufficient amount of diet was provided throughout the experimentation. Larval mortality was recorded every $24 \mathrm{~h}$ for seven days. Larvae without movements were considered dead.

\subsection{Isolate Selection}

Lethal and sublethal doses were calculated from the pre experimentation data. Isolate having the least $\mathrm{LC}_{50}$ with maximum mortality was selected for the downstream application.

\subsection{Experimental Validation of Lethal $\left(L C_{50}\right)$ and Sublethal $\left(L C_{20}\right)$ Concentrations}

Calculated lethal and sub-lethal concentrations were validated. Experimentation was carried out by following similar methodology described above. Each treatment included 15 larvae (3rd instar neonates) of $P$. xylostella. The experiment was replicated four times.

\subsection{Entomopathogenic Fungi Effect on Hemocyte Concentration of P. xylostella}

The hemocyte concentration in P. xylostella larvae was calculated on lethal $\left(\mathrm{LC}_{50}\right)$ concentration of M. anisopliae at different time points $(24,48,72$, and $96 \mathrm{~h}$ ). Larvae were surface sterilized with ethanol $(70 \%)$ and rinsed with double distilled water. Hemolymph was collected by dissection through proleg (30 larvae) using a sterilized blade and collected via glass capillary. Hemolymph was mixed with an equal amount of anticoagulant $(98 \mathrm{mM} \mathrm{NaOH}, 186 \mathrm{mM} \mathrm{NaCl}, 17 \mathrm{mM} \mathrm{Na} 2 \mathrm{EDTA}$, and $41 \mathrm{mM}$ citric acid, $\mathrm{pH}$ 4.5). Hemocyte concentrations were quantified using a hemocytometer with $10 \mu \mathrm{L}$ under a microscope [44]. The experiment was replicated four times.

\section{6. $P O$ and SOD Activity in P. xylostella Larvae}

Hemolymph was collected from 30 treated larvae. The collection was done after 24, 48, 72, and $96 \mathrm{~h}$ post-infection. Collected hemolymph was diluted ten times and studied under a microplate reader (BIO-RAD). PO activity was checked using L-dihydroxyphenylalanine (L-DOPA) as the substrate on the initial linear increase in absorbance at $490 \mathrm{~nm}$ [23]. SOD activities were observed using respective kits following the manufacturer's instructions (Suzhou Comin Biotech Co., Ltd., Suzhou, China). SOD activity was checked at a wavelength of $560 \mathrm{~nm}$ via a light reduction of nitro blue tetrazolium (NBT). NBT reduction (50\%) is the quantity of enzyme for each unit of SOD. Units/mg protein was used for both enzyme activities.

\subsection{Effect of M. anisopliae on the Expression of Immune-Related Genes in P. xylostella}

After infection of M. anisopliae, quantitative real-time PCR (qRT-PCR) was used to investigate the expression of immune-related genes (Cecropin, Defensin, Attacin, and Spaetzle). Total RNA was extracted from hemolymph and reverse-transcribed in a 25-uL reaction according to the manufacturer guideline (TaKaRa, Beijing, China). After reverse transcription, qRT-PCR was done by using (Bio-Rad 
iQ2 optical system (BioRad) with SsoFast Eva Green Supermix (Bio-Rad, Hercules, CA, USA). The working program was set as $95{ }^{\circ} \mathrm{C}$ for $2 \mathrm{~min}$, and 40 cycles of $95{ }^{\circ} \mathrm{C}$ for $5 \mathrm{~s}$, and $60{ }^{\circ} \mathrm{C}$ for $10 \mathrm{~s}$, melting curve from 65 to $95^{\circ} \mathrm{C}$ [45]. The expression of $\beta$-actin was selected to normalize the expression of the immune-related genes according to the $2^{-\Delta \Delta \mathrm{Ct}}$ method by Pfaffl, 2001 [46]. Three replicates were used in all experiments. Gene-specific primers were designed using Primer Premier 5. The gene sequences were subjected to Primer BLAST (www.ncbi.com) to check them for specificity The primers used are given in Table S1 [47].

\subsection{Effects of Lethal Concentration of M. anisopliae on Biological Parameters of P. xylostella}

The effects of lethal concentration of M. anisopliae was evaluated against P. xylostella. Each replication consists of 30 larvae of 3rd instar. For the treatment of fungi, the dip method was used. Petri dishes (diameter $5 \mathrm{~cm}$ ) cleaned $(70 \%$ ethanol) and air-dried for treating the larvae. Newly emerged cabbage leaves which were gently washed with double distilled water and air-dried served as larval diet. On emergence, the adults were paired (1 pair/cage) in plastic cages (cleaned with $70 \%$ ethanol and air-dried) for egg-laying. Sugar solution (10\%) was provided as an adult diet. Whatman filter tape was used as an egg-laying pad. Eggs were counted under a microscope and were placed in plastic boxes $(15 \mathrm{~cm} \times 10 \mathrm{~cm} \times 5 \mathrm{~cm})$ for hatching. Data were collected every $12 \mathrm{~h}$ until the end of the experiment. Immobile larvae were considered dead and placed in a humid chamber for conidial growth observation [48].

\subsection{Statistical Analysis}

Mortality data were analyzed by using Probit analysis [49]. Abbott formula was used for the correction of mortality $[50,51]$. Lethal and sublethal concentrations for all entomopathogenic fungi were calculated by using SPSS 17.0 (SPSS Inc., Chicago, IL, USA) and Polo Pc (Petaluma, CA, Canada) [52]. One-way ANOVA was used for mortality data, means were separated by Tukey's HSD test with a $5 \%$ level of significance $(p<0.05)$ [53]. Demographic data were analyzed by using Statistics 8.01 [53].

The hemocytes concentration and enzymatic activities (SOD and PO) after the treatment of M. anisopliae were analyzed by t-test. The relative expression of the selected immune genes was also analyzed via a t-test with a significance level set as $p<0.05$.

\section{Results}

\subsection{Screening of Entomopathogenic Fungi}

The results were highly concentration-dependent (Figure 1). M. anisopliae showed the highest mortality $(93.13 \%)$ at $4 \times 10^{8}$ (spores $\left./ \mathrm{mL}\right)$ followed by B. bassiana $(81.51 \%)$ while the least mortality $(77.52 \%)$ was observed in I. fumosorosea $(\mathrm{F}=89, \mathrm{DF}=4, p=0.001)$. Mortality in control and tween control was insignificant. For confirmation of fungal pathogenicity, the carcasses were placed in a humid chamber for the growth of conidia (Figure 2). 


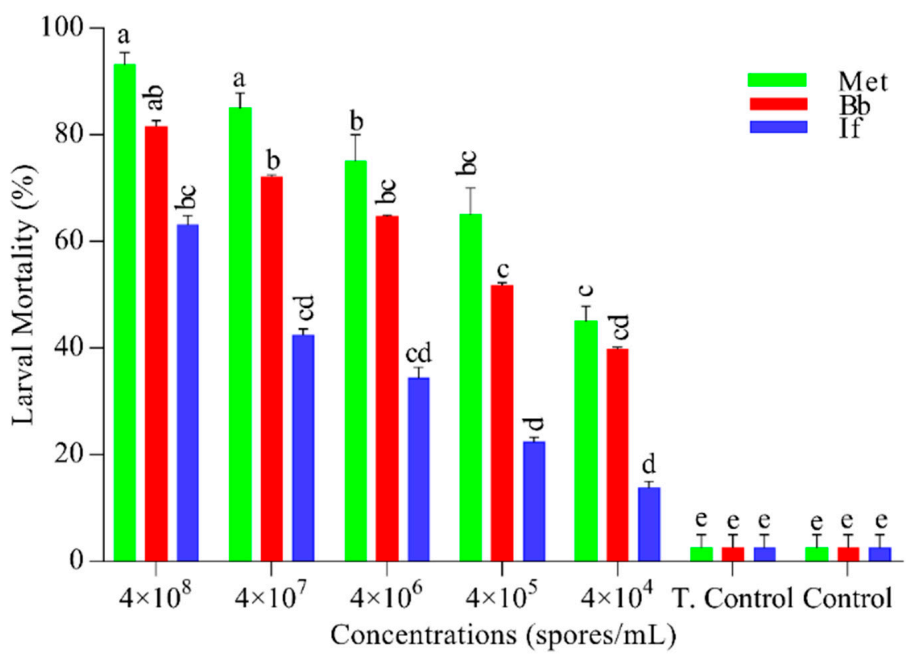

Figure 1. Larvicidal activity of entomopathogenic fungi. Mortality was recorded until seven days after every $24 \mathrm{~h}$. Green, red, and blue bars represent the larval mortality of Plutella xylostella, after exposure to different concentrations of Metarhizium anisopliae (Met), Beauveria bassiana (Bb), and Isaria fumosorosea (If) respectively. While T. Control is tween control ( $0.05 \%$ aqueous diluted) and in Control, distilled water was used. Error bars show 95\% confidence intervals (CI). Letters indicate significant differences at $p<0.05$.

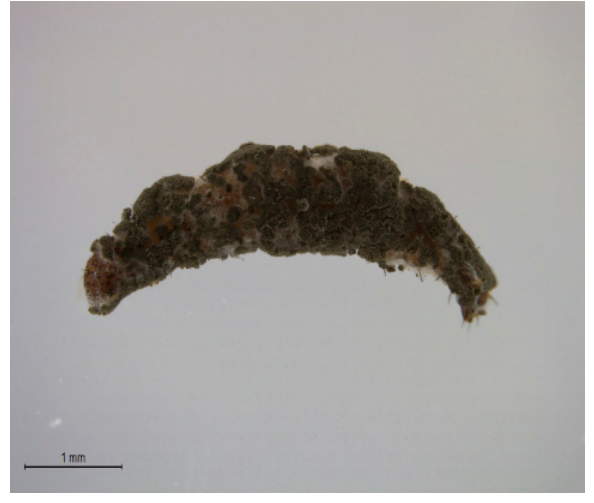

(A)

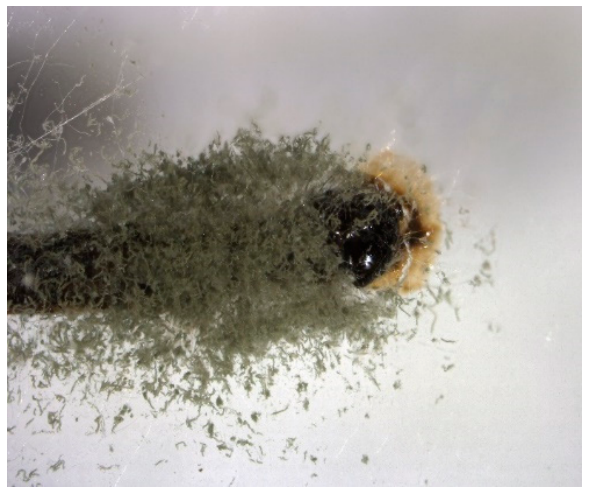

(C)

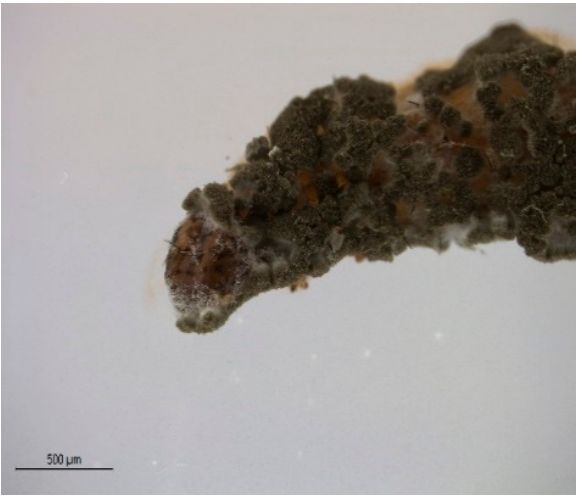

(B)

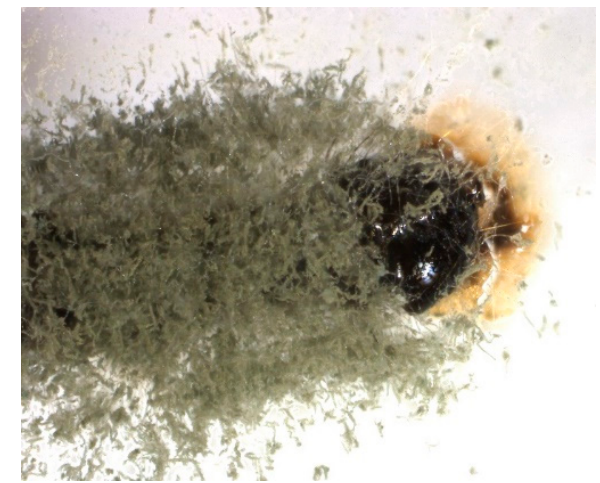

(D)

Figure 2. Conidial growth of Metarhizium anisopliae on larvae of Plutella xylostella. Larvae were placed in a humid chamber for confirmation of death due to fungi. (A) Conidial growth over the full body of the dead larvae. (B) Zoomed in the image of the conidia growing on the head of the dead larvae. (C) Conidial growth around the head and thorax of larvae. (D) Zoomed in the image of conidial growth adjacent to the head. 


\subsection{Selection of Entomopathogenic Fungi}

Based on pre experimentation data lethal $\left(\mathrm{LC}_{50}\right)$ and sublethal $\left(\mathrm{LC}_{20}\right)$ doses were calculated with (95\% CL). M. anisopliae was selected on the basis of designed criteria (Table 2) as it showed the highest percent mortality and least $\mathrm{LC}_{50}$.

Table 2. Lethal and sublethal concentrations of fungi against Plutella xylostella.

\begin{tabular}{ccccccc}
\hline Fungi & LC $_{\mathbf{5 0}}$ & LC $_{\mathbf{2 0}}$ & Slop \pm SE & $\chi^{\mathbf{2}}$ & $p$-Value & df \\
\hline Metarhizium anisopliae & $6.2 \times 10^{4}$ & $2.3 \times 10^{2}$ & $0.29 \pm 0.044$ & 2.1 & 0.001 & 4 \\
Beauveria bassiana & $9.3 \times 10^{5}$ & $3.1 \times 10^{3}$ & $0.38 \pm 0.044$ & 1.1 & 0.003 & 4 \\
Isaria fumosorosea & $7.9 \times 10^{6}$ & $4.6 \times 10^{4}$ & $0.42 \pm 0.046$ & 1.8 & 0.002 & 4 \\
\hline
\end{tabular}

\subsection{Experimental Validation of Lethal $\left(L C_{50}\right)$ and Sublethal $\left(L C_{20}\right)$ Concentrations of $M$. anisopliae}

Lethal and sublethal concentrations of $M$. anisopliae were validated, showing $51.74 \%$ and $32.11 \%$ larval mortality respectively (Supplementary Figure S1).

\subsection{Effects of M. anisopliae on Hemocyte Concentration of P. xylostella}

After infecting the larvae with lethal $\left(\mathrm{LC}_{50}\right)$ concentration of $M$. anisopliae, results for hemocyte count are shown (Figure 3). Non-significant (0.071) results were observed regarding the hemocytes count on all time points.

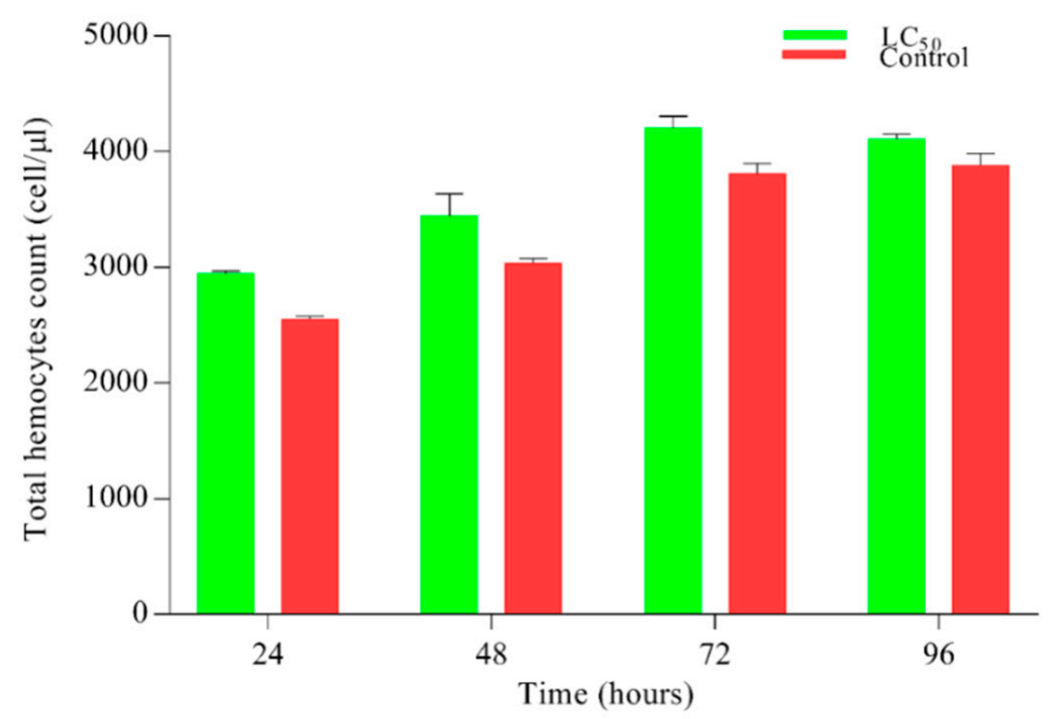

Figure 3. Hemocytes count in Plutella xylostella larvae after treatment with lethal $\left(\mathrm{LC}_{50}\right)$ concentration of Metarhizium anisopliae. Green bars represent the hemocytes count of larvae under the pressure of $\mathrm{LC}_{50}$ while red bars show tween control (0.05\% aqueous diluted) hemocytes count. Results were statistically non-significant $p<0$. 071. Error bars show 95\% confidence intervals (CI).

\subsection{Effects of M. anisopliae $\left(L_{50}\right)$ on the Activity of PO and SOD in Larvae of P. xylostella}

The activities of immune enzymes $\mathrm{PO}$ and SOD against $\mathrm{LC}_{50}$ of $M$. anisopliae are shown in Figure 4 . PO activity peaked at $24 \mathrm{~h}$, equaling control at $48 \mathrm{~h}$ while decreasing later on 48 and $72 \mathrm{~h}$. SOD activity amplified around $72 \mathrm{~h}$ post-treatment. Figure $4 \mathrm{~A}-\mathrm{D}$ shows the activity of enzymes at 24 , 48,72 , and 96 h respectively. 


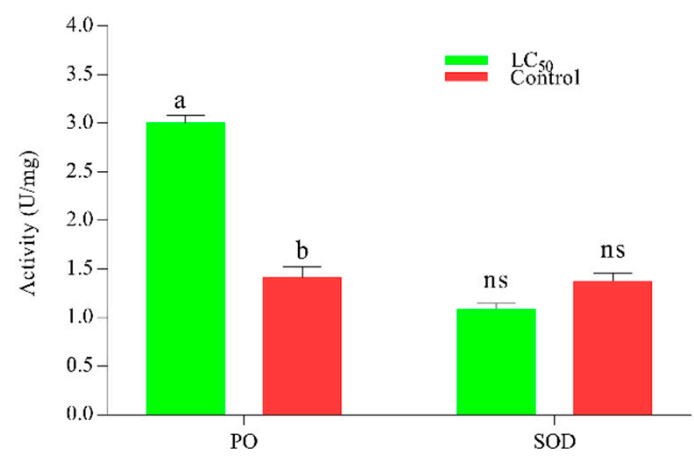

24 hours

(A)

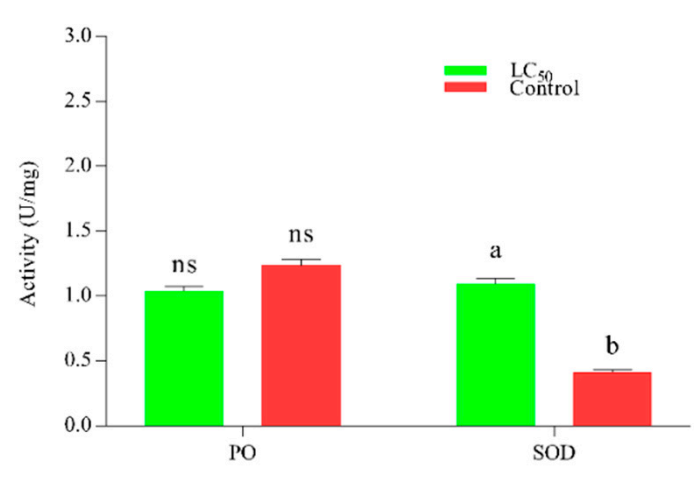

72 hours

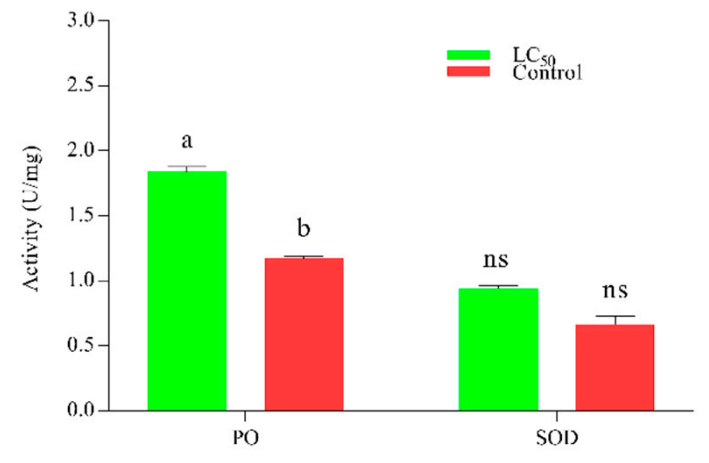

48 hours

(B)

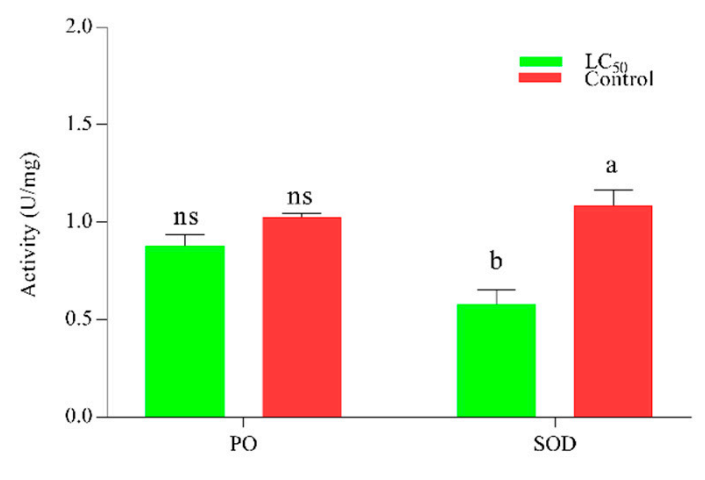

96 hours

(C)

(D)

Figure 4. Activity of phenoloxidase (PO) and superoxide dismutase (SOD) activity in Plutella xylostella against $\mathrm{LC}_{50}$ of Metarhizium anisopliae. Time-dependent activity is shown in the figure, the green color bar shows the activity of enzymes whereas the red bar represents the control. (A-D) shows the activities of enzymes after $24,48,72$, and 96 h respectively. Error bars show $95 \%$ confidence intervals (CI). Letters indicate significant differences at $p<0.005$. (ns = non-significant).

\subsection{Effect of Lethal Concentration of M. anisopliae on Immune Genes of P. xylostella}

The expression of all immune genes was predominantly time-dependent (Figure 5), with a significance level of 0.001. Defensin showed a substantial increase in expression after $24 \mathrm{~h}$ of treatment compared to control followed by a decrease at $72 \mathrm{~h}$ ultimately approaching non-significant expression at $96 \mathrm{~h}$. Spaetzle showed the highest expression at $24 \mathrm{~h}$ post-treatment among all the genes, gradually decreasing after $48 \mathrm{~h}$ and keep on decreasing until $96 \mathrm{~h}$. Cecropin expression level increased significantly until $72 \mathrm{~h}$ while decreasing later at $96 \mathrm{~h}$. Hemolin and lysozyme, both genes showed similar trends at 24 and 48, but both showed non-significant activity after 72- and 96-h post-treatment. 


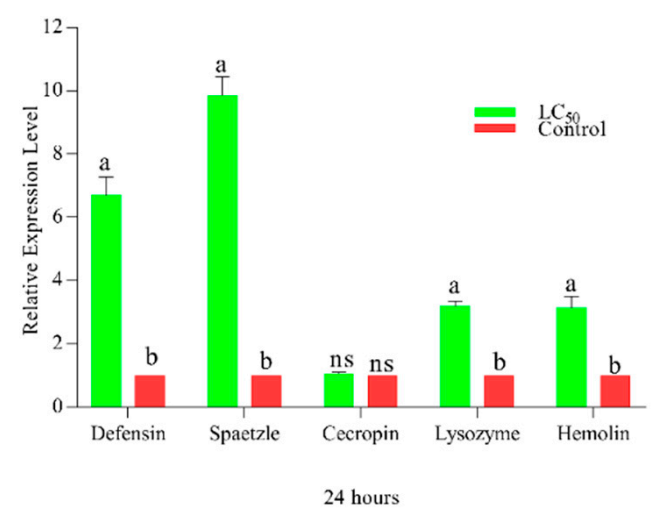

(A)

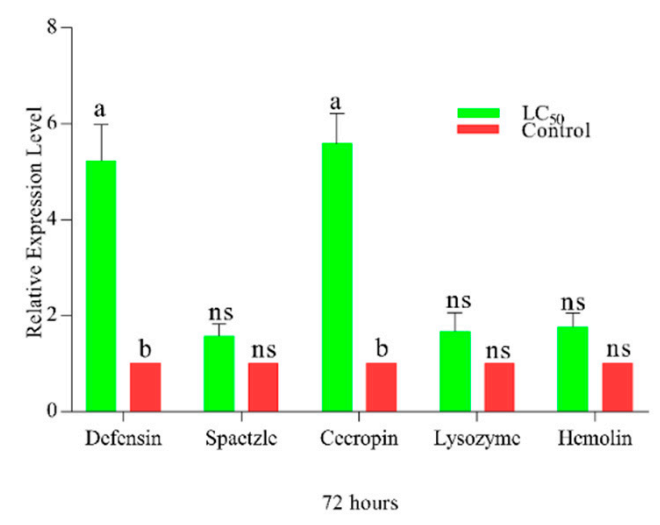

(C)

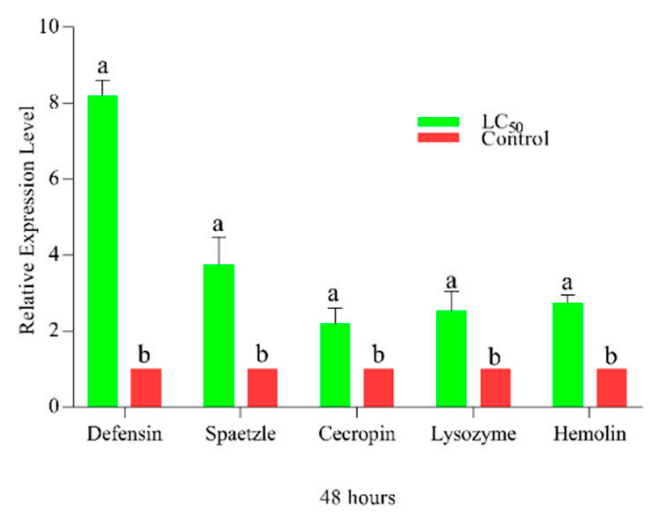

(B)

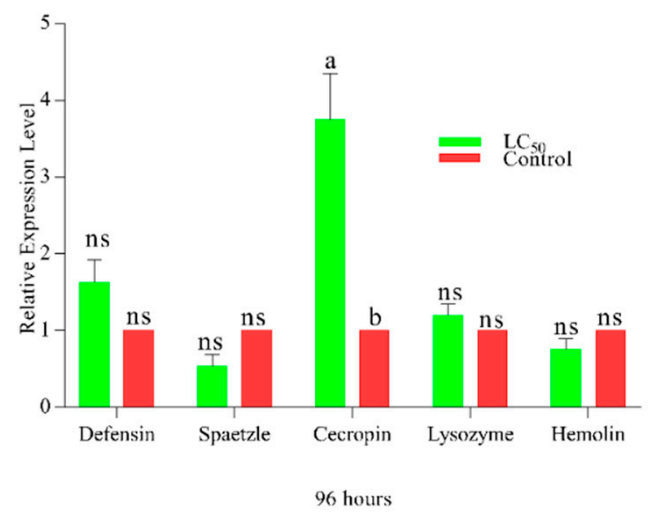

(D)

Figure 5. Immune genes expression in Plutella xylostella against $\mathrm{LC}_{50}$ of Metarhizium anisopliae. Time-dependent activity is shown in the figure, the green color bar shows the activity of gene at $\mathrm{LC}_{50}$ of M. anisopliae while the red bar shows the control. (A-D) shows the activities of enzymes after 24, 48,72 , and 96 h respectively. Error bars show 95\% confidence intervals (CI). Letters indicate significant differences at $p<0.001$. (ns = non-significant).

\subsection{The Lethal Concentration of M. anisopliae Affects the Biological Parameters of P. xylostella}

M. anisopliae $\left(\mathrm{LC}_{50}\right)$ disturbs the biological parameters of P. xylostella (Table 3). After the application of lethal concentration on 3rd instar, a significant reduction in larval duration (1.10 days) was observed compared to control ( 2.4 days) $(p>0.05)$. A similar trend was followed by 4 th instar. A considerable decrease in percent pupation was also reported in the infected population with only $64.21 \%$ larvae arriving at the pupal stage compared to $93.51 \%$ in control. Prolonged pupal duration (5.22 days) was followed by reduced adult emergence $(61.47 \%)$ with a ratio of $1: 2$ sex ratio (M: F). The pre-oviposition period (APOP) in adult females increased to 1.92 days compared to 1.01 days in control. Fecundity was also significantly affected in treated females where the mean number of eggs laid was reduced to $101.55 \mathrm{eggs} / \mathrm{female}$ in comparison to $192.55 \mathrm{eggs} / \mathrm{female}$ control. A noteworthy effect was also seen on egg hatching (first filial generation). The daily egg production rate is shown in Figure 6, where the number of eggs in control is significantly higher than the treated group. 
Table 3. Biological parameters of Plutella xylostella after treatment of Metarhizium anisopliae.

\begin{tabular}{ccc}
\hline Parameters & M. anisopliae $\left(\mathbf{L C}_{50}\right)$ & Control \\
\cline { 2 - 3 } & Means \pm SE & Means \pm SE \\
\hline Mortality (\%) & $51.34 \pm 1.25^{\mathrm{a}}$ & $5.4 \pm 0.10^{\mathrm{b}}$ \\
L3 (days) & $1.10 \pm 0.21^{\mathrm{b}}$ & $2.14 \pm 0.17^{\mathrm{a}}$ \\
L4 (days) & $1.72 \pm 0.11^{\mathrm{b}}$ & $2.59 \pm 0.12^{\mathrm{a}}$ \\
Percent pupation & $64.21 \pm 2.46^{\mathrm{b}}$ & $93.51 \pm 3.11^{\mathrm{a}}$ \\
Pupal duration (days) & $5.22 \pm 0.71^{\mathrm{a}}$ & $3.80 \pm 0.27^{\mathrm{b}}$ \\
Adult emergence (\%) & $61.47 \pm 3.41^{\mathrm{b}}$ & $92.11 \pm 3.57^{\mathrm{a}}$ \\
Female longevity (days) & $6.87 \pm 0.98^{\mathrm{b}}$ & $10.11 \pm 1.98^{\mathrm{a}}$ \\
Male longevity (days) & $8.11 \pm 1.27^{\mathrm{b}}$ & $12.38 \pm 2.8^{\mathrm{a}}$ \\
Sex ratio (M:F) & $1: 2^{\mathrm{ns}}$ & $1: 2^{\mathrm{ns}}$ \\
APOP & $1.92 \pm 0.04^{\mathrm{ns}}$ & $1.01 \pm 0.07^{\mathrm{ns}}$ \\
Fecundity (eggs/female) & $101.55 \pm 2.54^{\mathrm{b}}$ & $192.55 \pm 3.21^{\mathrm{a}}$ \\
Egg hatching (\%) & $60.2 \pm 3.44^{\mathrm{b}}$ & $94.22 \pm 2.98^{\mathrm{a}}$ \\
\hline
\end{tabular}

L3 = 3rd instar larval duration; L4 = 4th instar larval duration; APOP = adult pre-oviposition period of female adult; means in the same row followed by the same letter are not significantly different $(p>0.05)$.

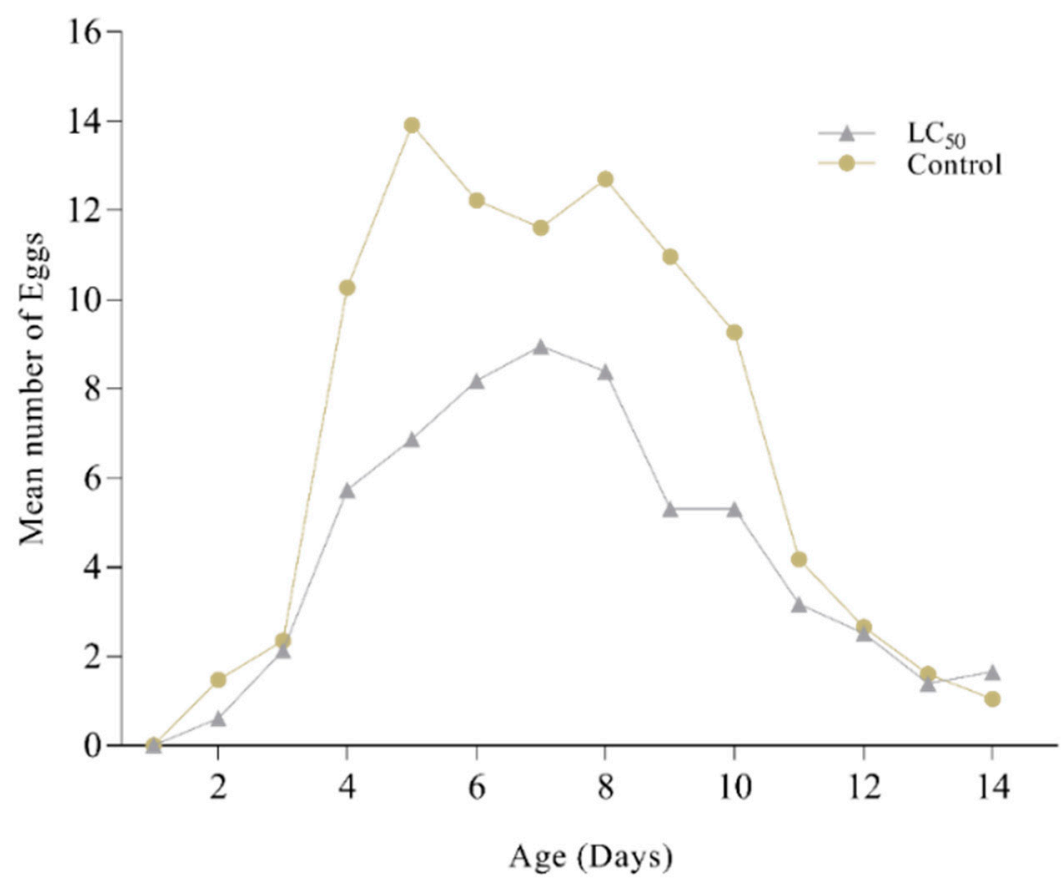

Figure 6. Mean number of eggs from Plutella xylostella after treatment with Metarhizium anisopliae. Grey dots show the mean numbers of eggs laid by P. xylostella after treatment by M. anisopliae while yellow dots show the control group.

\section{Discussion}

P. xylostella is a notorious pest of cruciferous crops [20]. IPM strategies employed to control this pest has been focused primarily on the use of chemical insecticides [8]. Compared to synthetic insecticides, pathogenic fungi are promising biocontrol agents for various insect pests and exhibit efficient capabilities for insecticide-resistant pests with fewer environmental hazards $[2,16]$. The study presented here evaluated three different types of entomopathogenic fungi for larval mortality in $P$. xylostella. Our results found that $M$. anisopliae could efficiently infect $P$. xylostella, and cause significant mortality compared to the rest, suggesting the potential of this entomopathogenic fungus for the pest control [3]. The difference in pathogenicity could be due to the fact that some fungal species germinate and penetrate more rapidly compared to others. Besides, an increase in the production 
of secondary metabolites to resist antifungal compounds is also the primary adaptive behavior of a potent entomopathogenic fungus [54-56]. Conversely, insect cuticle, a hydrophobic surface, acts as the first line of defense against invading fungi [33,57]. Entomopathogenic fungi encounter this barrier by producing hydrophobin proteins that synergies with enzymes, leading to infection and causing the death of the insect $[33,57]$. The mortality caused by M. anisopliae was highly concentration-dependent as previously described in other insect pests $[10,43,58]$. Insects possess an innate immune system, a dynamic and instantaneous mechanism against pathogenic infections [59]. The suppression of immune responses is one of the major mechanisms which govern the outcome of an interaction between pathogen and host $[60,61]$.

Hemocytes, upon invasion, play a vital role to defuse the pathogen activities by employing different biological processes such as phagocytosis and encapsulation [62,63]. Arthropods can produce various types of hemocytes depending upon the type of infection they face [64]. Studies have revealed that the number and types of hemocytes varied when infected with different strains and strengths of Metarhizium spp. [65].The ability of a pathogenic fungi to overcome host hemolymph also represents its virulence to the host [66]. The study presented here showed a change in hemocyte numbers under pressure from the lethal concentration of $M$. anisopliae, which could be due to evasion and overcoming hemolymph defense systems by entomopathogenic fungus. However, this change was not statistically significant, supported by similar findings in previous studies [67].

The enzymatic responses are a key constituent of the insect immune system under various stressful environments, reflecting physiological changes in the host. Enzymes such as PO play a crucial role in wound deposition, encapsulation of pathogens, and most importantly activation of immune pathways [68]. The increased PO activity strengthens the ability of the immune system to counter xenobiotics [69,70], while its inhibition suggests pathogenic fungi may overcome the immunity of PO. The current study depicted a time-based trend in PO activity rising to a maximum between 24 and $48 \mathrm{~h}$ while gradually decreasing at 72 and $96 \mathrm{~h}$, indicating that $M$. anisopliae steadily get the better of the host defense system [69]. Similarly, SOD an antioxidant defense enzyme, also reported varying trends demonstrating that the physiological activities of $P$. xylostella larvae were distressed following the infection by fungi [71,72]. Insect immune responses are governed by various immune genes expressed at different time points. Scientists have been able to identify 1000 immune-related genes in P. xylostella when targeted by entomopathogenic fungi [34]. Likewise, our study found out key genes (spaetzle, defensin, cecropin) involved in immune responses against entomopathogenic fungi were exceedingly time-dependent, showing varying expression levels.

M. anisopliae produces secondary metabolite destruxin, a compound capable of evading insect cellular and humoral immune responses, troubling the demographic parameters of the pest before its eventual death [73-76]. Disturbances in biological parameters of various insect pests have been reported when infected with entomopathogenic fungi $[10,11,26,61,62]$, which strengthens our findings where a distress in biological cycles are reported. During the invasion of pathogens (M. anisopliae) the body temperature of insects rises to encounter the infection but this, in turn, affects the larval stadium [77] supporting the current findings where reduced larval duration was observed. M. anisopliae absorbs hemolymph sugar content from tracheoles, reducing nutrients and leading toward early pupation, prolonged pupal duration $[35,78]$, reduced percent pupation, and percent emergence in different insect pests $[2,79,80]$ supporting the findings reported in a study presented here. Besides intrusion in immature stages, the adults are also affected in the form of shorter life span, an observation supported by previous findings where reduced adult age and fecundity were reported $[43,57,80,81]$.

\section{Conclusions}

The study conducted demonstrates the interaction of fungal pathogen M. anisopliae with immune responses of $P$. xylostella and potentially overcoming it by causing the disturbance in its demography eventually killing the host. Hence, M. anisopliae can become a potent prospect for the control of 
this pest. The study will provide a basic hence important information for further field and semi field experimentation.

Supplementary Materials: The following are available online at http://www.mdpi.com/2075-4450/11/10/0694/s1, Figure S1: Experimental validation of lethal (LC50) and sublethal (LC20) concentrations of Metarhizium anisopliae. Error bars show 95\% confidence intervals (CI), Table S1: Primers used in this study.

Author Contributions: Conceptualization, J.Z.; data curation, J.Z. and R.F.S.; formal analysis, J.Z.; funding acquisition, X.X. and F.J.; investigation J.Z. and Y.Z.; methodology, J.Z.; project administration, S.F. and F.J.; resources, X.X. and F.J.; supervision, F.J.; writing-original draft, J.Z. All authors have read and agreed to the published version of the manuscript.

Funding: This work was supported by grants from the Key-Area Research and Development Program of Guangdong Province (2018B020205003), Natural Science Foundation of Guangdong, China (2018A030313402, 2019A1515011221) and State Key Laboratory of Biocontrol (Sun Yat-sen University) (2019SKLBC-KF02).

Acknowledgments: We are very grateful to Laboratory of Bio-Pesticide Creation and Application of Guangdong Province, Guangzhou, China for support. We also thank editors and anonymous referees for their invaluable comments and suggestion.

Conflicts of Interest: The authors declare no conflict of interest.

\section{References}

1. Freed, S.; Feng Liang, J.; Shun Xiang, R. Intraspecific Variability among the Isolates of Metarhizium anisopliae var. anisopliae by RAPD Markers. Int. J. Agric. Biol. 2014, 16, 899-904.

2. Shoukat, R.F.; Hassan, B.; Shakeel, M.; Zafar, J.; Li, S.; Freed, S.; Xu, X.; Jin, F. Pathogenicity and Transgenerational Effects of Metarhizium anisopliae on the Demographic Parameters of Aedes albopictus (Culicidae: Diptera). J. Med. Entomol. 2020, 57, 677-685. [PubMed]

3. Shoukat, R.F.; Freed, S.; Ahmad, K.W. Evaluation of binary mixtures of entomogenous fungi and botanicals on biological parameters of Culex pipiens (Diptera: Culicidae) under laboratory and field conditions. Int. J. Mosq. Res. 2016, 3, 17-24.

4. Shoukat, R.F.; Freed, S.; Ahmad, K.W.; Rehman, A.-U. Assessment of Binary Mixtures of Entomopathogenic Fungi and Chemical Insecticides on Biological Parameters of Culex pipiens (Diptera: Culicidae) under Laboratory and Field Conditions. Pak. J. Zool. 2018, 50, 299-309. [CrossRef]

5. Zafar, J.; Freed, S.; Khan, B.A.; Farooq, M. Effectiveness of Beauveria bassiana Against Cotton Whitefly, Bemisia tabaci (Gennadius) (Aleyrodidae: Homoptera) on Different Host Plants. Pak. J. Zool. 2016, 48, 91-99.

6. Khan, B.A.; Freed, S.; Zafar, J.; Farooq, M.; Shoukat, R.F.; Ahmad, K.W.; Li, S.; Zhang, Y.; Hua, Y.; Shoukat, R.F. Efficacy of different entomopathogenic fungi on biological parameters of pulse beetle Callosobruchus chinensis L. (Coleoptera: Bruchidae). J. Entomol. Zool. Stud. 2018, 6, 1972-1976.

7. Khan, B.A.; Freed, S.; Zafar, J.; Farooq, M. Evaluation of three different insect pathogenic fungi for the control of Dysdercus koenigii and Oxycarenus hyalinipennis. Pak. J. Zool 2014, 46, 1759-1766.

8. Duarte, R.; Gonçalves, K.; Espinosa, D.; Moreira, L.; De Bortoli, S.; Humber, R.; Polanczyk, R. Potential of entomopathogenic fungi as biological control agents of diamondback moth (Lepidoptera: Plutellidae) and compatibility with chemical insecticides. J. Econ. Entomol. 2016, 109, 594-601.

9. Rizvi, S.A.H.; Xie, F.; Ling, S.; Zeng, X. Development and evaluation of emulsifiable concentrate formulation containing Sophora alopecuroides L. extract for the novel management of Asian citrus psyllid. Environ. Sci. Pollut. Res. 2019, 21, 21871-21881. [CrossRef]

10. Shoukat, R.F.; Zafar, J.; Shakeel, M.; Zhang, Y.; Freed, S.; Xu, X.; Jin, F. Assessment of Lethal, Sublethal, and Transgenerational Effects of Beauveria Bassiana on the Demography of Aedes Albopictus (Culicidae: Diptera). Insects 2020, 11, 178. [CrossRef]

11. Shoukat, R.F.; Shakeel, M.; Rizvi, S.A.H.; Zafar, J.; Zhang, Y.; Freed, S.; Xu, X.; Jin, F. Larvicidal, Ovicidal, Synergistic, and Repellent Activities of Sophora alopecuroides and Its Dominant Constituents Against Aedes albopictus. Insects 2020, 11, 246.

12. Bakkali, F.; Averbeck, S.; Averbeck, D.; Idaomar, M. Biological effects of essential oils-A review. Food Chem. Toxicol. 2008, 46, 446-475. [CrossRef] [PubMed]

13. Relyea, R.; Hoverman, J. Assessing the ecology in ecotoxicology: A review and synthesis in freshwater systems. Ecol. Lett. 2006, 9, 1157-1171. [PubMed] 
14. Sukumar, K.; Perich, M.J.; Boobar, L.R. Botanical derivatives in mosquito control: A review. J. Am. Mosq. Control Assoc. 1991, 7, 210-237. [PubMed]

15. Thomas, M.B.; Read, A.F. Can fungal biopesticides control malaria? Nat. Rev. Microbiol. 2007, 5, 377. [PubMed]

16. Zimmermann, G. Review on safety of the entomopathogenic fungi Beauveria bassiana and Beauveria brongniartii. Biocontrol Sci. Technol. 2007, 17, 553-596. [CrossRef]

17. Ahmed, S.M.; Saeed, M.; Nawaz, A.; Usman, M.; Shoukat, R.F.; Li, S.; Zhang, Y.; Zeng, L.; Zafar, J.; Akash, A. Monitoring of quantitative and qualitative losses by lepidopteran, and homopteran pests in different crop production systems of Brassica oleracea L. J. Entomol. Zool. Stud. 2018, 6, 6-12.

18. Malik, S.U.; Zia, K.; Ajmal, M.; Shoukat, R.F.; Li, S.; Saeed, M.; Zafar, J.; Shoukat, R.F. Comparative efficacy of different insecticides and estimation of yield losses on BT and non-BT cotton for thrips, red cotton bug, and dusky cotton bug. J. Entomol. Zool. Stud. 2018, 6, 505-512.

19. Saeed, M.; Shoukat, R.F.; Zafar, J. Population dynamics of natural enemies and insect pest in different Brassica oleracea (cabbage) growing seasons with different production systems. J. Entomol. Zool. Stud. 2017, 5, 1669-1674.

20. Sarfraz, M.; Keddie, A.B.; Dosdall, L.M. Biological control of the diamondback moth, Plutella xylostella: A review. Biocontrol Sci. Technol. 2005, 15, 763-789.

21. Zhang, S.; Zhang, X.; Shen, J.; Li, D.; Wan, H.; You, H.; Li, J. Cross-resistance and biochemical mechanisms of resistance to indoxacarb in the diamondback moth, Plutella xylostella. Pestic. Biochem. Physiol. 2017, 140, 85-89. [PubMed]

22. Ashfaq, M.; Sonoda, S.; Tsumuki, H. Expression of two methionine-rich storage protein genes of Plutella xylostella (L.) in response to development, juvenile hormone-analog and pyrethroid. Comp. Biochem. Physiol. Part B Biochem. Mol. Biol. 2007, 148, 84-92. [CrossRef] [PubMed]

23. Liu, S.; Niu, H.; Xiao, T.; Xue, C.; Liu, Z.; Luo, W. Does phenoloxidase contributed to the resistance? Selection with butane-fipronil enhanced its activities from diamondback moths. Open Biochem. J. 2009, 3, 9. [CrossRef] [PubMed]

24. Ahmad, K.W.; Freed, S.; Shoukat, R.F. Efficacy of entomopathogenic fungi and botanicals on development of Musca domestica. J. Entomol. Zool. Stud. 2017, 5, 593-599.

25. Farooq, M.; Freed, S. Mortality, Biological, and Biochemical Response of Musca domestica (Diptera: Muscidae) to Selected Insecticides 1. J. Entomol. Sci. 2018, 53, 27-45. [CrossRef]

26. Farooq, M.; Freed, S. Insecticidal activity of toxic crude proteins secreted by entomopathogenic fungi against musca domestica 1. (Diptera: Muscidae). Kuwait J. Sci. 2018, 45, 64-74.

27. Farooq, M.; Steenberg, T.; Castberg, D.; Freed, S.; Kristensen, M. Impact of sequential exposure of Beauveria bassiana and imidacloprid against susceptible and resistant strains of Musca domestica. BioControl 2018, 63, 703-718. [CrossRef]

28. Freed, S.; Farooq, M. Entomopatojen fungus ve sentetik insektisit karışımlarının Musca domestica L.'nın biyolojik dönemleri üzerinde lethal ve sublethal etkileri. Türkiye Entomoloji Derg. 2016, 40, 211-225.

29. Zimmermann, G. Review on safety of the entomopathogenic fungus Metarhizium anisopliae. Biocontrol Sci. Technol. 2007, 17, 879-920.

30. Fite, T.; Tefera, T.; Negeri, M.; Damte, T.; Sori, W. Evaluation of Beauveria bassiana, Metarhizium anisopliae, and Bacillus thuringiensis for the management of Helicoverpa armigera (Hubner)(Lepidoptera: Noctuidae) under laboratory and field conditions. Biocontrol Sci. Technol. 2020, 30, 278-295.

31. Freed, S.; Saleem, M.A.; Khan, M.; Naeem, M. Prevalence and effectiveness of Metarhizium anisopliae against Spodoptera exigua (Lepidoptera: Noctuidae) in southern Punjab, Pakistan. Pak. J. Zool. 2012, 44, 753.

32. Lu, H.-L.; Leger, R.S. Insect immunity to entomopathogenic fungi. In Advances in Genetics; Elsevier: Amsterdam, The Netherlands, 2016; Volume 94, pp. 251-285.

33. Butt, T.M.; Greenfield, B.P.J.; Greig, C.; Maffeis, T.G.G.; Taylor, J.W.D.; Piasecka, J.; Dudley, E.; Abdulla, A.; Dubovskiy, I.M.; Garrido-Jurado, I.; et al. Metarhizium anisopliae Pathogenesis of Mosquito Larvae: A Verdict of Accidental Death. PLoS ONE 2013, 8, e81686. [CrossRef]

34. Xu, J.; Xu, X.; Shakeel, M.; Li, S.; Wang, S.; Zhou, X.; Yu, J.; Xu, X.; Yu, X.; Jin, F. The entomopathogenic fungi Isaria fumosorosea plays a vital role in suppressing the immune system of Plutella xylostella: RNA-Seq and DGE analysis of immunity-related genes. Front. Microbiol. 2017, 8, 1421. [PubMed]

35. Peng, G.; Jin, K.; Liu, Y.; Xia, Y. Enhancing the utilization of host trehalose by fungal trehalase improves the virulence of fungal insecticide. Appl. Microbiol. Biotechnol. 2015, 99, 8611-8618. 
36. Broxton, C.N.; Culotta, V.C. SOD enzymes and microbial pathogens: Surviving the oxidative storm of infection. PLoS Pathog. 2016, 12, e1005295. [CrossRef]

37. Robinett, N.G.; Peterson, R.L.; Culotta, V.C. Eukaryotic copper-only superoxide dismutases (SODs): A new class of SOD enzymes and SOD-like protein domains. J. Biol. Chem. 2018, 293, 4636-4643. [CrossRef]

38. Wu, K.; Yang, B.; Wang, J.; Luo, Y.; Ni, Y.; Huang, W. Detection of Enzyme Distribution, Expression, Activation, and Activity of Insect Prophenoloxidase. In Immunity in Insects; Springer: Berlin/Heidelberg, Germany, 2020; pp. 115-126.

39. González-Rete, B.; Salazar-Schettino, P.M.; Bucio-Torres, M.I.; Córdoba-Aguilar, A.; Cabrera-Bravo, M. Activity of the prophenoloxidase system and survival of triatomines infected with different Trypanosoma cruzi strains under different temperatures: Understanding Chagas disease in the face of climate change. Parasites Vectors 2019, 12, 219.

40. Butt, T.; Ibrahim, L.; Ball, B.; Clark, S. Pathogenicity of the entomogenous fungi Metarhizium anisopliae and Beauveria bassiana against crucifer pests and the honey bee. Biocontrol Sci. Technol. 1994, 4, 207-214. [CrossRef]

41. Darbro, J.M.; Thomas, M.B. Spore persistence and likelihood of aeroallergenicity of entomopathogenic fungi used for mosquito control. Am. J. Trop. Med. Hyg. 2009, 80, 992-997. [CrossRef]

42. Scholte, E.-J.; Knols, B.G.; Takken, W. Infection of the malaria mosquito Anopheles gambiae with the entomopathogenic fungus Metarhizium anisopliae reduces blood feeding and fecundity. J. Invertebr. Pathol. 2006, 91, 43-49. [CrossRef]

43. Scholte, E.-J.; Takken, W.; Knols, B.G. Infection of adult Aedes aegypti and Ae. albopictus mosquitoes with the entomopathogenic fungus Metarhizium anisopliae. Acta Trop. 2007, 102, 151-158.

44. Ibrahim, A.M.; Kim, Y. Parasitism by Cotesia plutellae alters the hemocyte population and immunological function of the diamondback moth, Plutella xylostella. J. Insect Physiol. 2006, 52, 943-950. [CrossRef] [PubMed]

45. Li, S.; Xu, X.; Zheng, Z.; Zheng, J.; Shakeel, M.; Jin, F. MicroRNA expression profiling of Plutella xylostella after challenge with B. thuringiensis. Dev. Comp. Immunol. 2019, 93, 115-124. [PubMed]

46. Pfaffl, M.W. A new mathematical model for relative quantification in real-time RT-PCR. Nucleic Acids Res. 2001, 29, e45.

47. Ye, J.; Coulouris, G.; Zaretskaya, I.; Cutcutache, I.; Rozen, S.; Madden, T.L. Primer-BLAST: A tool to design target-specific primers for polymerase chain reaction. BMC Bioinform. 2012, 13, 134. [CrossRef] [PubMed]

48. Golizadeh, A.; Kamali, K.; Fathipour, Y.; Abbasipour, H. Life table of the diamondback moth, Plutella xylostella (L.)(Lepidoptera: Plutellidae) on five cultivated brassicaceous host plants. J. Econ. Entomol. 2009, 112, 932-938.

49. Ai, C.; Norton, E.C. Interaction terms in logit and probit models. Econ. Lett. 2003, 80, 123-129. [CrossRef]

50. Abbott, W. Abbott's formula. J. Econ. Entomol. 1925, 18, 267-268.

51. Abbott, W. A method of computing the effectiveness of an insecticide. J. Am. Mosq. Control Assoc. (USA) 1987, 3, 302-303.

52. LeOra Software LLC. Poloplus, A User's Guide to Probit or Logit Analysis; LeOra Software LLC: Berkeley, CA, USA, 2003.

53. Statistical Analysis System Institute. SAS/STAT User's Guide: Statistics, version 8.1; Statistical Analysis System Institute: Cary, NC, USA, 2000.

54. Liu, X.; Wang, H.-Y.; Ning, Y.-B.; Qiao, K.; Wang, K.-Y. Resistance selection and characterization of chlorantraniliprole resistance in Plutella xylostella (Lepidoptera: Plutellidae). J. Econ. Entomol. 2015, 108, 1978-1985. [CrossRef]

55. Ortiz-Urquiza, A.; Keyhani, N.O. Action on the surface: Entomopathogenic fungi versus the insect cuticle. Insects 2013, 4, 357-374. [CrossRef] [PubMed]

56. Aw, K.M.S.; Hue, S.M. Mode of infection of Metarhizium spp. fungus and their potential as biological control agents. J. Fungi 2017, 3, 30. [CrossRef] [PubMed]

57. Rozilawati, H.; Masri, M.; Tanaselvi, K.; TH, M.Z.; Zairi, J.; Nazni, W.; Lee, H. Life Table Characteristics of Malaysian Strain Aedes albopictus (Skuse). Serangga 2018, 22, 85-121.

58. O'Brien, D.; McVey, J. Blood Coagulation, Inflammation, and Defense; The Natural Immune System, Humoral Factors; IRL Press: New York, NY, USA, 1993; pp. 257-280. 
59. Wang, C.; Leger, R.J.S. A collagenous protective coat enables Metarhizium anisopliae to evade insect immune responses. Proc. Natl. Acad. Sci. USA 2006, 103, 6647-6652.

60. Huang, S.; He, Z.; Zhang, S.; Keyhani, N.O.; Song, Y.; Yang, Z.; Jiang, Y.; Zhang, W.; Pei, Y.; Zhang, Y. Interplay between calcineurin and the Slt2 MAP-kinase in mediating cell wall integrity, conidiation and virulence in the insect fungal pathogen Beauveria bassiana. Fungal Genet. Biol. 2015, 83, 78-91.

61. Strand, M.R. The insect cellular immune response. Insect Sci. 2008, 15, 1-14.

62. Kwon, B.; Kim, Y. Transient expression of an EP1-like gene encoded in Cotesia plutellae bracovirus suppresses the hemocyte population in the diamondback moth, Plutella xylostella. Dev. Comp. Immunol. 2008, 32, 932-942.

63. Fiorotti, J.; Menna-Barreto, R.F.S.; Gôlo, P.S.; Coutinho-Rodrigues, C.J.B.; Bitencourt, R.O.B.; Spadacci-Morena, D.D.; Angelo, I.d.C.; Bittencourt, V.R.E.P. Ultrastructural and cytotoxic effects of Metarhizium robertsii infection on Rhipicephalus microplus hemocytes. Front. Physiol. 2019, 10, 654.

64. Cao, G.; Jia, M.; Zhao, X.; Wang, L.; Tu, X.; Wang, G.; Nong, X.; Zhang, Z. Correction: Different Effects of Metarhizium anisopliae Strains IMI330189 and IBC200614 on Enzymes Activities and Hemocytes of Locusta migratoria L. PLoS ONE 2017, 12, e0175219. [CrossRef]

65. Samson, R.A.; Evans, H.C.; Latgé, J.-P. Atlas of Entomopathogenic Fungi; Springer Science \& Business Media: Berlin/Heidelberg, Germany, 2013.

66. Yu, Y.; Cao, Y.; Xia, Y.; Liu, F. Wright-Giemsa staining to observe phagocytes in Locusta migratoria infected with Metarhizium acridum. J. Invertebr. Pathol. 2016, 139, 19-24. [CrossRef]

67. Cerenius, L.; Lee, B.L.; Söderhäll, K. The proPO-system: Pros and cons for its role in invertebrate immunity. Trends Immunol. 2008, 29, 263-271. [PubMed]

68. Cerenius, L.; Söderhäll, K. The prophenoloxidase-activating system in invertebrates. Immunol. Rev. 2004, 198, 116-126. [CrossRef] [PubMed]

69. Chang, C.-C.; Rahmawaty, A.; Chang, Z.-W. Molecular and immunological responses of the giant freshwater prawn, Macrobrachium rosenbergii, to the organophosphorus insecticide, trichlorfon. Aquat. Toxicol. 2013, 130, 18-26. [CrossRef] [PubMed]

70. Jiang, W.; Peng, Y.; Ye, J.; Wen, Y.; Liu, G.; Xie, J. Effects of the Entomopathogenic Fungus Metarhizium anisopliae on the Mortality and Immune Response of Locusta migratoria. Insects 2020, 11, 36. [CrossRef]

71. Wang, H.; Zhang, H.; Hao, C.; Zhang, X. Effects of Isaria fumosorosea infection on different enzyme activities in the larvae of Plutella xylostella. Mycosystema 2013, 32, 269-276.

72. Keppanan, R.; Krutmuang, P.; Sivaperumal, S.; Hussain, M.; Bamisile, B.S.; Aguila, L.C.R.; Dash, C.K.; Wang, L. Synthesis of mycotoxin protein IF8 by the entomopathogenic fungus Isaria fumosorosea and its toxic effect against adult Diaphorina citri. Int. J. Biol. Macromol. 2019, 125, 1203-1211.

73. Alves, S.; Alves, L.; Lopes, R.; Pereira, R.; Vieira, S. Potential of some Metarhizium anisopliae isolates for control of Culex quinquefasciatus (Dipt., Culicidae). J. Appl. Entomol. 2002, 126, 504-509.

74. Leles, R.N.; D'Alessandro, W.B.; Luz, C. Effects of Metarhizium anisopliae conidia mixed with soil against the eggs of Aedes aegypti. Parasitol. Res. 2012, 110, 1579-1582. [CrossRef]

75. Luz, C.; Tai, M.; Santos, A.; Rocha, L.; Albernaz, D.; Silva, H. Ovicidal activity of entomopathogenic hyphomycetes on Aedes aegypti (Diptera: Culicidae) under laboratory conditions. J. Med. Entomol. 2007, 44, 799-804. [CrossRef]

76. Mousseau, T.A.; Dingle, H. Maternal Effects in Insect Life Histories. Annu. Rev. Entomol. 1991, 36, 511-534. [CrossRef]

77. Jin, K.; Peng, G.; Liu, Y.; Xia, Y. The acid trehalase, ATM1, contributes to the in vivo growth and virulence of the entomopathogenic fungus, Metarhizium acridum. Fungal Genet. Biol. 2015, 77, 61-67. [CrossRef] [PubMed]

78. Malarvannan, S.; Murali, P.; Shanthakumar, S.; Prabavathy, V.; Nair, S. Laboratory evaluation of the entomopathogenic fungi, Beauveria bassiana against the Tobacco caterpillar, Spodoptera litura Fabricius (Noctuidae: Lepidoptera). J. Biopestic. 2010, 3, 126.

79. Darbro, J.M.; Johnson, P.H.; Thomas, M.B.; Ritchie, S.A.; Kay, B.H.; Ryan, P.A. Effects of Beauveria bassiana on survival, blood-feeding success, and fecundity of Aedes aegypti in laboratory and semi-field conditions. Am. J. Trop. Med. Hyg. 2012, 86, 656-664. [PubMed] 
80. Howard, A.F.; N'Guessan, R.; Koenraadt, C.J.; Asidi, A.; Farenhorst, M.; Akogbéto, M.; Thomas, M.B.; Knols, B.G.; Takken, W. The entomopathogenic fungus Beauveria bassiana reduces instantaneous blood feeding in wild multi-insecticide-resistant Culex quinquefasciatus mosquitoes in Benin, West Africa. Parasites Vectors 2010, 3, 87. [CrossRef]

81. de Paula, A.R.; Brito, E.S.; Pereira, C.R.; Carrera, M.P.; Samuels, R.I. Susceptibility of adult Aedes aegypti (Diptera: Culicidae) to infection by Metarhizium anisopliae and Beauveria bassiana: Prospects for Dengue vector control. Biocontrol Sci. Technol. 2008, 18, 1017-1025.

(c) (C) 2020 by the authors. Licensee MDPI, Basel, Switzerland. This article is an open access article distributed under the terms and conditions of the Creative Commons Attribution (CC BY) license (http://creativecommons.org/licenses/by/4.0/). 